Boise State University

ScholarWorks

$1-8-2015$

\title{
Human Rights in the Context of Environmental Conservation on the US-Mexico Border
}

Lisa Meierotto

Boise State University 


\title{
Human Rights in the Context of Environmental Conservation on the US-Mexico Border
}

\author{
Lisa Meierotto, Ph.D.
}

Boise State University

\begin{abstract}
At Cabeza Prieta National Wildlife Refuge, a wilderness area on the US-Mexico border in Arizona, conflicting policies permit the provision of supplementary water for wildlife but not for undocumented immigrants passing through the area. Federal refuge environmental policy prioritizes active management of endangered and threatened species. Vast systems of water resources have been developed to support wildlife conservation in this extremely hot and dry environment. At the same time, humanitarian groups are not allowed to supply water to undocumented border crossers in the park. Human border-crossers must utilize non-potable wildlife water "guzzlers" for survival and face a real risk of illness or death by dehydration. This article analyzes human rights via an ethnographic lens. From this perspective, water policy at the wildlife refuge brings into question the value of human life in a border conservation context, especially for those entering the site "illegally."
\end{abstract}

\section{Introduction and Background}

Crossing the US-Mexico border is dangerous, risky, and at times deadly. The tales of these grueling treks are impossible to erase from one's mind (Annerino 1999; Urrea 2004; Regan 2010). Border security is complex and challenging and is predominately described as inefficient and flawed in terms of meeting dual objectives of providing security and protecting human rights (Heyman 1998; Martinez 2006; Andreas 2009; Dunn 2009; Maril 2011). Border crossing presents a serious risk of injury or death for undocumented immigrants. Thousands of men, women, and children, most of Mexican and Latin American origin, have died since US immigration border and security agencies began to promote a "prevention through deterrence" (Nevins 2002: 2) policy in the 1990s. From the federal government's perspective, border policy aims to stem the tide of undocumented immigrants into the United States. However, when one delves deeper into the social, political, and environmental ramifications of the prevention through deterrence policy, a number of human rights issues are raised. This article considers just one of the many current human rights issues in the US-Mexico border region: availability and allocation of safe drinking water to undocumented border-crossers.

Complex environmental problems complicate human rights issues in the borderlands. The Arizona border region is located within the Sonoran Desert, a fragile desert landscape featuring a mosaic of federally protected wilderness areas, state parks, and national wildlife refuges. The land here is essentially under environmental assault. Undocumented immigration has a significant environmental impact on protected lands. Impacts range from discarded litter to vehicle traffic damage by human smugglers (Cornelius 2001; Sundberg and Kaserman 2007). But perhaps more significantly, border-enforcement activities degrade the natural landscape through law enforcement activities such as fence building, surveillance activities, and the pursuit of smugglers and immigrants with a vast array of Border Patrol vehicles (Meierotto 2012).

Cabeza Prieta National Wildlife Refuge (NWR) is one of several federally protected wilderness areas in southern Arizona. The refuge spans over 800,000 acres and shares 56 contiguous miles with the Mexican border. The human rights and environmental situation at Cabeza Prieta is emblematic of the complexity of the social and political turmoil existing in the American borderlands. At Cabeza Prieta, the social and political aims of nature conservation intersect with and at times conflict with human rights efforts. The refuge has been subjected to significant amounts of environmental degradation as a result of undocumented immigration, human and drug smuggling, and Border Patrol policies and practices (Meierotto 2012). Wildlife refuge policy has also been criticized for its human rights record, especially for restrictions on allowing humanitarian groups access to provide potable water for bordercrossers. 
This article focuses on the controversy over conflicting policies at Cabeza Prieta that permit the allocation of supplementary water for animals but not for humans within the boundaries of the refuge. The article begins with a description of Cabeza Prieta and then discusses refuge water policy. Current management policy permits the distribution of supplementary water for the protection and recovery of endangered and threatened wildlife. At the same time, refuge policy prohibits humanitarian transport and import of potable drinking water to humans (specifically to undocumented immigrants crossing from Mexico into the United States). Further, it is argued by some conservationists that the trucks and plastic bottles used for human-designated supplementary water challenge traditional ideas about a "leave-no-trace" approach to wilderness (see Cronon 1996 for a thoughtful critique of the wilderness paradigm).

The decision to not provide potable water to humans at Cabeza Prieta has been upheld in federal courts. In 2001, 11 undocumented immigrants died in Cabeza Prieta (the story of their death is chronicled in Alberto Luis Urrea's 2004 book The Devil's Highway). Families of the decedents later sued the US government. The families argued that the manager of Cabeza Prieta caused the deaths of the immigrants in his decision to deny humanitarian aid groups access to the refuge for the placement of emergency water stations. The case was eventually dismissed on the following grounds:

[The] defendant's concerns about the safety of aliens (who might be encouraged to cross the area because of the presence of water drums), the safety of refuge visitors (who have been victimized by a small percentage of illegal crossers), and environmental harm (arising from habitat disruption and littering of debris) gave Defendant the discretion to decline to authorize the erection of water drums on Cabeza Prieta, and therefore the Court has no jurisdiction to hear this case. (AmbrosMarcial et al. v. United States 2005: Summary)

Importantly, in this case, it was found that "a landowner has no duty to aid trespassers" (Ambros-Marcial et al. v. United States 2005: Sec. 2b). The "land owner," the US government, successfully argued in court that because Cabeza Prieta is a wilderness area, water stations might not be "compatible" with wildlife refuge purpose and policy. Further, if water stations were allowed, potential harms might arise. For example, the water could be poisoned harming the "aliens." Or alternative argument, increased immigrant activity could "have a negative impact on wilderness character, destruction of vegetation, and threats to the Sonoran Pronghorn habitat" (an endangered species) (Ambros-Marcial et al. v. United States 2005: Sec. 2.15). However, the fact that the refuge already provides supplementary water to wildlife-and this activity has an impact on the wilderness character of the land-is not discussed in the court case. In this article, I ask the following question: If wilderness transgression is already occurring on behalf of wildlife,

why not for humans?

Lastly, the article connects water policy priorities to a broader discussion of ethnicity, race, and human rights. On a more symbolic level, ethnographic data demonstrate how the "dehumanization" of undocumented immigrants in the American borderlands is evident through the employment of dehumanizing metaphors to describe so-called "illegals." In other words, the life-value ascribed to specific people crossing through the desert-especially Mexican people-is low. I argue that this dehumanization helps to diffuse what might otherwise be a stronger moral imperative to provide supplementary water for humans crossing through the refuge.

Ultimately, this article also contributes to a broader discussion on the human right to water among migrant populations. While this case study is specific to the US-Mexico border, the general topic raises broader human rights concerns that are discussed throughout the article. There is little current literature on the issue of the human right to water among migrant populations crossing international borders. This article contributes to the beginnings of that discussion.

\section{Research Site and Design}

Cabeza Prieta is one of 300 Wildlife Refuges nationwide and is a nationally designated Wilderness area. The name of the refuge, Cabeza Prieta, refers to a dark-colored mountain on the western side of the refuge. Cabeza Prieta is translated from Spanish to English as "Dark Head." The refuge was established in 1939 for the protection and management of desert resources. At 860,010 acres, it is the third largest wildlife refuge in the continental United States. Public lands surrounding the refuge include Organ Pipe National Monument and the Goldwater Air Force 
range. The refuge is also bordered by the Tohono O'odham Nation. The southern border of the refuge is adjacent to the U.S.-Mexico border (see Figure 1). Highway Number 2 in Mexico cuts the landscape from East to West across the Sonoran Desert and roughly parallels the international border. A variety of state and federal land-use agencies bear responsibility for managing conservation sites and wilderness areas in the Sonoran Desert region.

The data presented in this article and the subsequent analysis and discussion are based on ethnographic research conducted at Cabeza Prieta National Wildlife Refuge between January 2007 and May 2009. Observations presented in the article are drawn from participant observation and unstructured interviews with several refuge staff, US Border Patrol agents, and humanitarian aid groups working in the greater region. Finally, I include references to mainstream media related to the issue of supplementary water, as well as government publications on water policy at Cabeza Prieta.

\section{Figure One: Map of Cabeza Prieta, Obtained from US Fish and Wildlife Services}

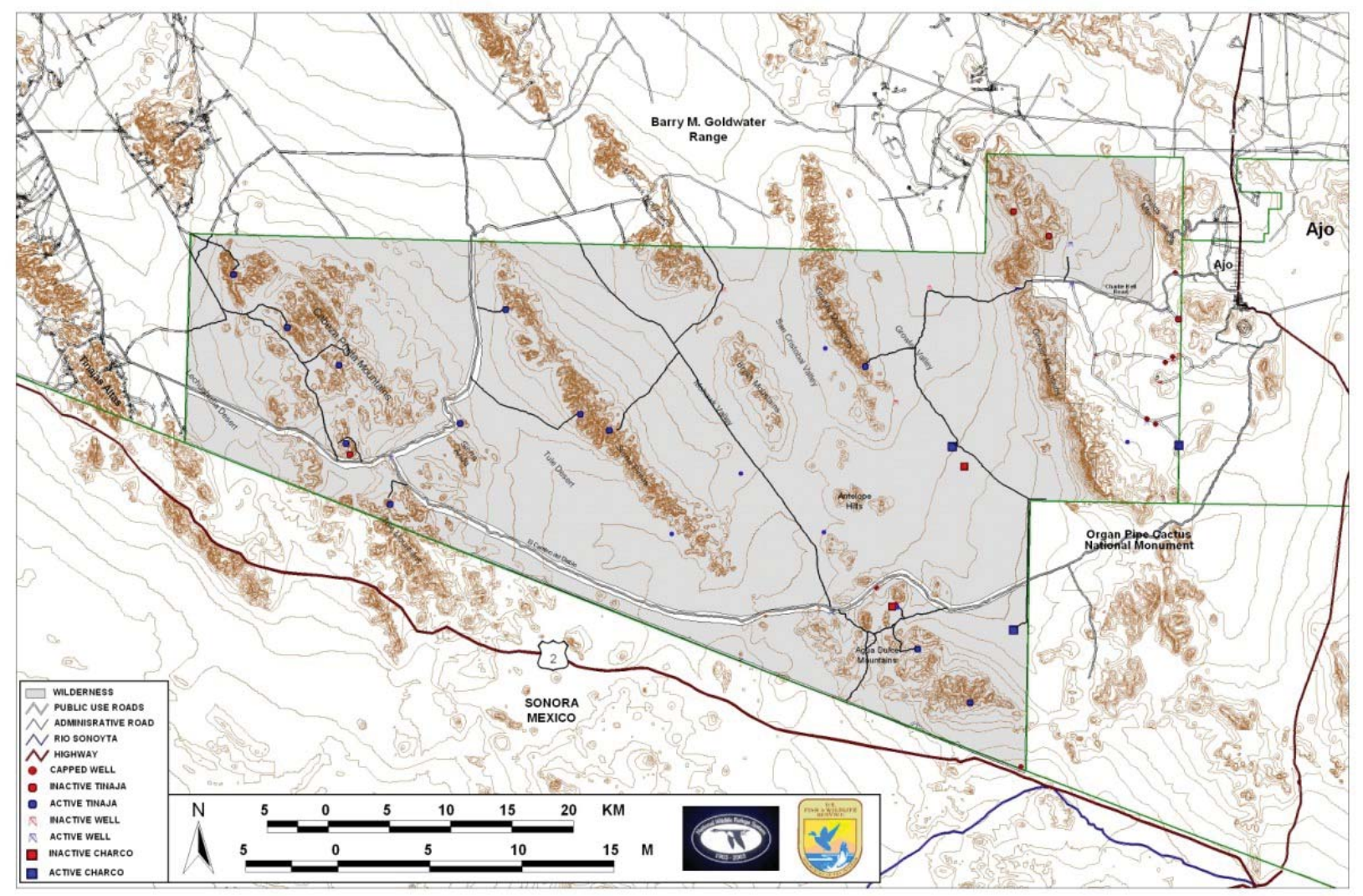

The ideas presented in this article are mine alone and do not reflect those of any individual or organization working in wildlife conservation programs in the borderlands. Any analysis or critique of this situation is not intended as an ethical judgment towards the hard-working individuals who are committed to preserving wildlife and natural resources along the US-Mexico border. These individuals negotiate complex situations every single day and their work is to be commended. I attempt to maintain as neutral a position as possible in the discussion, though certainly my analysis offers a critical interpretation of the current federal priorities in water disbursement from a human rights perspective. In this messy terrain of morals, values, and ethics, I hope to offer an opportunity for conservationists to explore a relevant human rights issue and vice versa. 


\section{Water as a Human Right and Conflicting Policy of Supplementary Water at Cabeza Prieta}

Cabeza Prieta NWR is governed by federal wilderness and conservation regulations. Under the guidelines set forth in the National Wildlife Refuge System Administration Act of 1966, conservation of wildlife and its habitat is the first priority of the refuge system (US Fish and Wildlife 2007: 14). While some public use is allowed on refuge land, the main focus is preserving wildlife and recreational opportunities connected to their preservation (such as hunting, wildlife observation, and photography). But when these guidelines were established, migration through the USMexico border was not a major policy issue. During the 1990s, US-Mexico border policy changed. The approach is commonly referred to as the "prevention through deterrence" approach to border enforcement. In short, the new border policy sealed off popular urban border crossing points and funneled immigrants through the harsh, isolate, and dangerous Arizona desert (Cornelius 2001, Nevins 2002, Martinez 2006, Regan 2010). The intent of the policy change was to make desert crossing so difficult that fewer people would attempt to cross illegally. In reality, the policy has resulted in greater numbers of people crossing and smuggling through wilderness areas. The prevention through deterrence policy has resulted in more deaths and humanitarian conflicts throughout the desert border region. There is an astounding death toll of over 1,715 migrants in southern Arizona from 2002 to 20091 (Lacey 2010) and the number of deaths resulting from immigration policy have doubled since 1995 (USGAO 2006). Complicating the immigration issue is the fact humanitarian aid groups operating in the borderlands must navigate and negotiate with the multiple land-use agencies responsible for the carved up landscape. For example, wildlife refuges are managed differently than national parks and monuments, and there is also Bureau of Land Management (BLM) land, state land, and private land. The following two sections discuss how these moral negotiations have played a role in conservation management at Cabeza Prieta.

\section{Water for Wildlife}

Even though Cabeza Prieta is a wilderness area (and, as such, per federal law should remain largely untouched by human activity), there is a large network of informal administrative roads across the refuge. Some of these roads are historic, and even prehistoric, such as the notorious Camino del Diablo, which was used as a migration route for early native Americans, a travel route for early Spanish missionaries, and later by fortune seekers during the California gold rush (Urrea 2004). In part because the existence of these roads made wilderness travel possible, when the refuge was created in 1939, the management plan called for water structure development and "active management" of wildlife (US Fish and Wildlife 2007: 6). The refuge practices what staff term "active management" in the recovery and protection of endangered and threatened species (US Fish and Wildlife 2007: 23). The original motivation was the protection of bighorn sheep for hunting stock. While desert bighorn sheep are not currently endangered, they are recognized as a "wilderness resource." The water programs developed to aid bighorn sheep now aid many different species of wildlife, most notably the endangered Sonoran Desert Pronghorn.

There are some natural water sources in the areas, pools of water called tinajas. While some are reliable, no water on the refuge could be classified as permanent. Water is ephemeral and subject to unreliable and highly variable rainfall. Beyond the few natural sources of water across the refuge, there are 22 developed watering stations (often referred to colloquially as "guzzlers") maintained by refuge staff. These sites were originally developed to aid in the maintenance of big-horn sheep, the first protected species on the refuge (protected in the sense that the refuge was originally established as a game range for sheep hunting). The refuge added another 10 emergency water sites since 2003, in response to hotter and drier weather conditions. Though the waters are often quite rancid, they are used by humans in emergency situations. Recreational visitors are required to carry several gallons of water for each day they will be on the refuge, but border-crossers from Mexico are often unaware (or misled) about water requirements and, thus, are more likely to need supplementary water. The climate is so dry and hot that dehydration occurs rapidly and severely, and death by exposure and dehydration is a very real possibility.

Human-created water sources are identified as one of five types of water developments:

- Buried reservoirs with collection points and drinking troughs;

- Runoff tanks;

- Charcos (dug-out ponds);

- Wells with drinking troughs;

- Storage tanks with drinking troughs. 
Wildlife water sites were originally designed to blend into the landscape as naturally as possible, though over time fiberglass tanks and drinkers have been added to deal with water shortages in the dry months (US Fish and Wildlife 2007: 44). In terms of management and decision making, refuge personnel determine when to haul in water by truck based on visual observation of the water sites, taking into consideration temperature and precipitation levels. Currently, between 9 and 18 hauling trips are made on an annual basis. It is reasonable to assume that increasing amounts of water will be needed in the face of climate change, which is expected to result in hotter, drier conditions in the southwest (Environmental Protection Agency 2013). Evidence of this recent development is the construction (since 2003) of 10 "emergency" water sites specifically created for endangered Sonoran Pronghorn (see Figure 2).

Some conservation scholars have criticized the development of water sources, and the issue has been subject to substantial management, public, and scholarly discussion (Mattson and Chambers 2009). On the one hand, some conservationists question the extent to which the supplementary water actually helps wildlife like bighorn sheep (Broyles 1995). Some have even claimed that the supplementary water has a negligible effect on helping bighorn populations (Broyles and Cutler 1999). It has been argued for both bighorn sheep and Sonoran pronghorn, that the animals may be able to gain sufficient water from foraging, and thus the supplementary water is less important to their survival than management plans suggest. However, it is important to note that many other animals utilize the supplementary water, and the refuge is in the process of developing a camera monitoring system to document total use of water sites. Others argue that these water sources are necessary to counteract the negative anthropogenic harm caused in fragile desert areas, like climate change (making the desert hotter and drier) and habitat fragmentation (Dolan 2006). There are also concerns regarding the water sources themselves, for example, leading to increased predation or animals becoming trapped in water developments (see Dolan 2006 for a review of these critiques).

Figure 2. Map of water sites. United States Department of the Interior Fish and Wildlife Service. Reproduced by permission of United States Department of the Interior Fish and Wildlife Service.
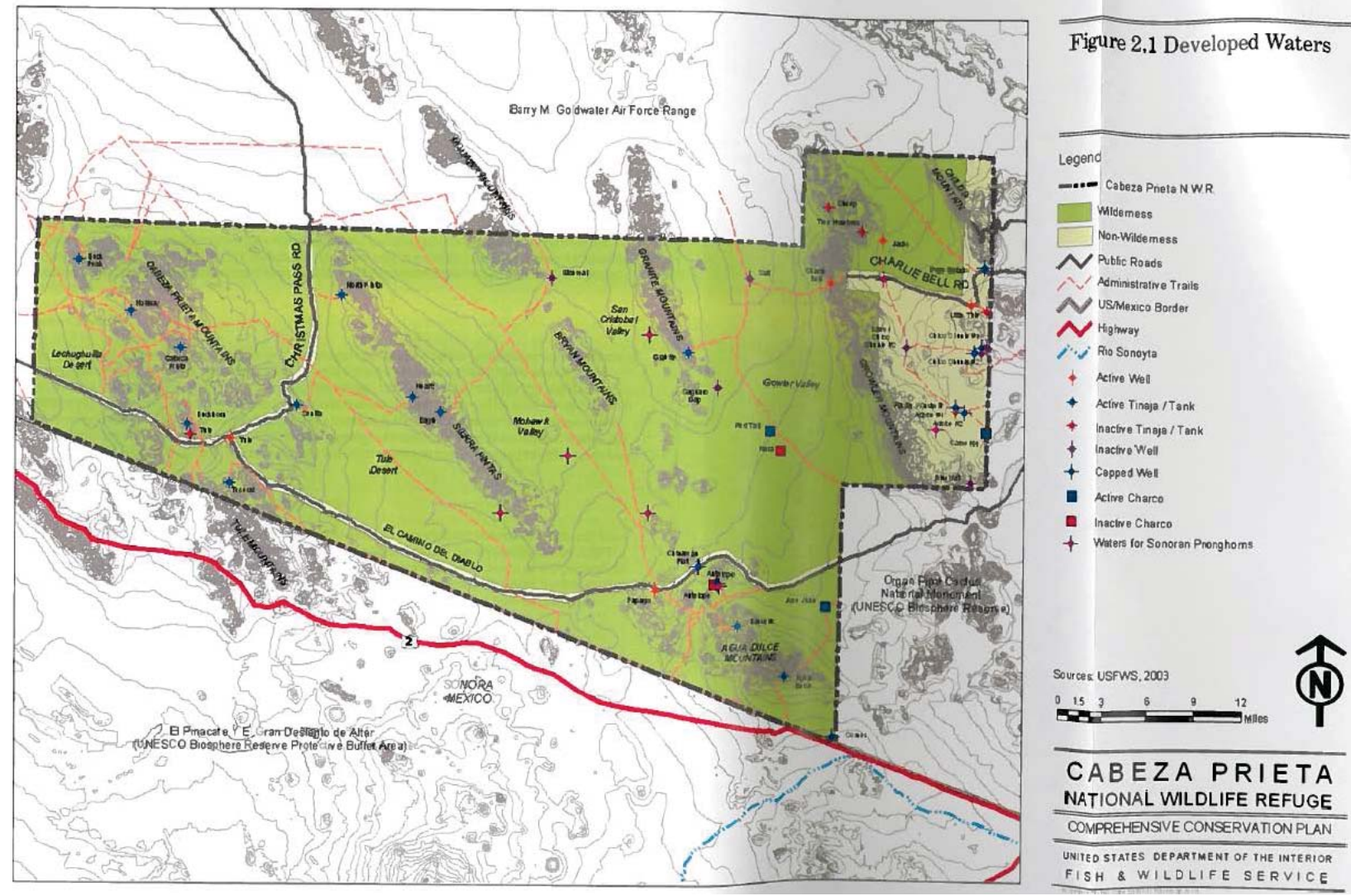

This case study offers an interesting point of tension between conservationists and animal rights activists. Animal rights activists consider the ethics of how humans "use" animals for their own benefit and focus on reducing animal suffering (Pivetti 2005). This is a useful way to frame the practice of providing supplemental water at Cabeza Prieta. 
Original wildlife conservation goals were for the explicit purpose of increasing stock for hunting. But today, and especially in the context of climate change, the discourse has shifted somewhat to incorporate consideration of the welfare of wildlife in the refuge. As the Sonoran Desert region becomes hotter and drier in coming years, animal suffering and death can be prevented/reduced by the provision of supplementary water.

To get a better sense of the complexity of supplementary water provision to wildlife, in October of 2007 I visited a remote Sonoran pronghorn breeding pen at the refuge along with an Arizona Game and Fish technician. This individual's job was to monitor and maintain the pen. The pen is a one square mile enclosure seemingly in the middle of nowhere, surrounded by a 7,000 volt electric fence. We began the day's chores by walking the perimeter of the enclosure, looking for attempts to breach the security system. Coyotes will attempt to enter to cull young pronghorn, as do bobcats and mountain lions. Humans often attempt to enter the enclosure-usually undocumented border-crossers seeking access to the water inside the pen. After checking the perimeter, we inspected irrigation pipes. Pipes are most often damaged by undocumented immigrants and smugglers, drawn to a rare water source in this arid environment. Finally, we climbed a small hill just south of the pen and set up the scoping equipment. All the pronghorn must be counted and observed to see that they are in good health. The entire process takes about five hours and must be completed before the heat of the day sets in. Four technicians, all employees of Arizona Game and Fish, carry out this routine each day of the year on a rotating schedule and intervene whenever it is necessary. Interventions include repairing irrigation pipes and the fence, supplying supplementary feeding when natural foliage is sparse and removing deceased pronghorn. Pronghorn in the pen typically die from disease or from stress when attempts are made to remove them from the pen. Occasionally a predator, such as a hawk, kills a young pronghorn. The technicians keep track of births and deaths and also informally track the lineage of individual pronghorns. Maintenance of the pen and observation of the pronghorn are popular volunteer activities, bringing awareness of the species' plights to the wider public. The presence of undocumented immigrants at the pen is seen as a type of nuisance, not unlike a hawk or a bobcat—a logistical and physical challenge to wildlife conservation.

\section{Water for Humans}

Access to clean drinking water and sanitation is widely considered a basic human right. United Nations resolution 64/293 passed in 2010 "acknowledge[s] the importance of equitable access to safe and clean drinking water and sanitation as an integral component of the realization of all human rights" (United Nations 2010: 2). In other words, universal human rights cannot be achieved without the explicit consideration of access to clean drinking water. Beyond the official doctrine of the United Nations, the issue of access to water stems across time and geography throughout human history. "The human right to water, like many other human rights, is rooted in natural law concepts, community ethics and religious beliefs” (Beail-Farkas 2013: 771).

While it may be accepted in the international policy arena that water is a basic human right, a sweeping policy such as this inherently brings up questions of responsibility and enforcement. The case study of access to water in Cabeza Prieta raises several interesting questions on the topic. For example, does the United States have an obligation to provide undocumented immigrants clean water on well-known and well-established migration routes? What are the rights of undocumented immigrants in general, whether their travel path leads them cross-country or cross border?

The United Nations places the onus of responsibility for providing clean drinking water on the nation-state. Countries are obliged to provide "to provide safe, clean, accessible and affordable drinking water and sanitation for all” (United Nations 2010: 3). The issue of water has been of primary importance to the United Nations over the past decade. Campaigns and programs include the 2003 "International Year of Freshwater" and 2005-2015 as the "International Decade for Action, 'Water for Life”' (United Nations 2010). Typically, when the topic of access to clean drinking water comes into mind, images of remote villages and developing nations come to mind.

But this article raised questions of access to clean drinking water for transient populations in affluent nations. This issue-access to clean water and sanitation for international migrant populations-has not been thoroughly explored and merits further research beyond the case at hand.

While the issue of water for international migrants warrants further discussion, the issue of providing water for immigrants in Arizona has been discussed at great length in the national and local media (e.g., McCombs 2010; Lacey 2010). To learn more about the local issue of providing supplementary water for humans, in January 2008, I volunteered with the humanitarian aid group Humane Borders. We spent a long day driving along Highway 286 in 
southern Arizona (located to the east of Cabeza Prieta). It was quiet that day on the highway with very little traffic. In our blue and white well-equipped truck, we passed several border patrol vehicles and Pima County sheriff cars. At some point we passed one birdwatcher scanning the horizon with binoculars, but otherwise it was a very desolate and typical day in the desert. Yet, in spite of the relative calm of the day, the task at hand was startling. Humane Borders provides emergency water stations on desert routes known to be used by undocumented immigrant along portions of the US-Mexico border (Humane Borders 2015).

Our volunteer group that day was assigned to refill water tanks along popular bordercrossing routes, as well as to carry provisions to hand out to any border-crossers we might encounter any while doing the water rounds. We began the trip at a small Tucson church. At daybreak, we prepared one of the organization's four trucks, filling the tanks with water and provisions. In addition to the water brought in to refill the tanks at various locations, the truck also carries water bottles and food packs. The food packs contain items like canned food, crackers, and even a new pair of socks for the weary feet of a desert border-crosser. Most of the water stations we visited were on or near the highway near the border town of Sasabe, a currently popular route. We never went further than a half mile off the highway. The Humane Borders coordinator explained to our group that within the boundaries of Cabeza Prieta and most other federally protected land, humanitarian groups are not allowed to bring in supplementary water for human immigrants.2 This has created a major problem of access. At one point, the water controversy at Cabeza Prieta became so heated it resulted in a lawsuit against the Department of Interior and US federal government. The absence of humanitarian aid was cited as a cause of death for the 14 undocumented immigrants who died in 2001 while crossing Cabeza Prieta. As described in the introduction, the plaintiffs claimed that the manager of Cabeza Prieta was responsible for the deaths of the aliens and that refuge policy "caused their deaths by refusing to allow an immigrant rights group to erect water drums on the refuge in April 2001" (Ambros-Marcial et al. v. United States 2005: Summary). The case against the manager of Cabeza Prieta was ultimately dismissed on the ground that he used proper discretion in prohibiting humanitarian groups from providing water at the refuge. In addition, the courts ruled that the manager had no responsibility to "affirmatively assist trespassers illegally crossing Cabeza Prieta in avoiding the obvious dangers of a hostile desert” (Ambros-Marcial et al. v. United States 2005: para. 2).

The manager of Cabeza Prieta at that time denied humanitarian access on the following grounds. It is worth reproducing the entire list (Ambros-Marcial et al. v. United States 2005: Background), as several points highlight the irony of the practice of wilderness transgression for the sake of wildlife but not for humans:

(1) increased traffic through the Refuge to and from the stations could:

(a) adversely affect the Sonoran Pronghorn;

(b) produce untold negative consequences on refuge resources, similar to those caused by water for wildlife;

(c) exacerbate problems of trash, fires, habitat destruction, etc., in the vicinity of the stations;

(2) approval would need an endangered Species consultation;

(3) stations would aid and could increase illegal border crossing;

(4) stations could endanger the illegal aliens if:

(a) the stations were expected but were found empty;

(b) someone contaminated the stations;

(5) other sources of water in the Refuge were already known and illegally being used by smugglers and border crossers;

(6) Wilderness character would be impaired by the large drums and blue flags;

(7) Refuge law enforcement officers opposed the stations;

(8) the Bureau of Land Management experienced non-compliance with similar permit restrictions, and might decide not to renew the permits;

(9) establishing stations might lead to long term liability for the Refuge to maintain them; and

(10) the proposed locations would conflict with use by visitors.

Even though this case was eventually dismissed, perhaps its most important legacy was the decision to allow humanitarian groups to provide water qualifies as "discretionary" (Tiller Memo 2001 as cited in Ambros-Marcial et al. v. United States 2005: 3.a(i)). 
After the lawsuit was dismissed, refuge management developed an alternative policy for allowing supplementary water for border-crossers. While they still do not allow aid organizations to bring in water, they began to allow Humane Borders to use their signature blue flags to mark wildlife water stations within refuge boundaries (see Figure 3). The flags are high enough to be seen from a long distance, and most border-crossers know to seek them out if they run out of water. These guzzlers are often quite putrid, and there are no records kept on how often they are used. But evidence of migrant camp sites can be found around the guzzlers, so it is reasonable to assume they are being used.

Figure 3. Photo of flagged water tank. Source: Wilderness.net Image Library.

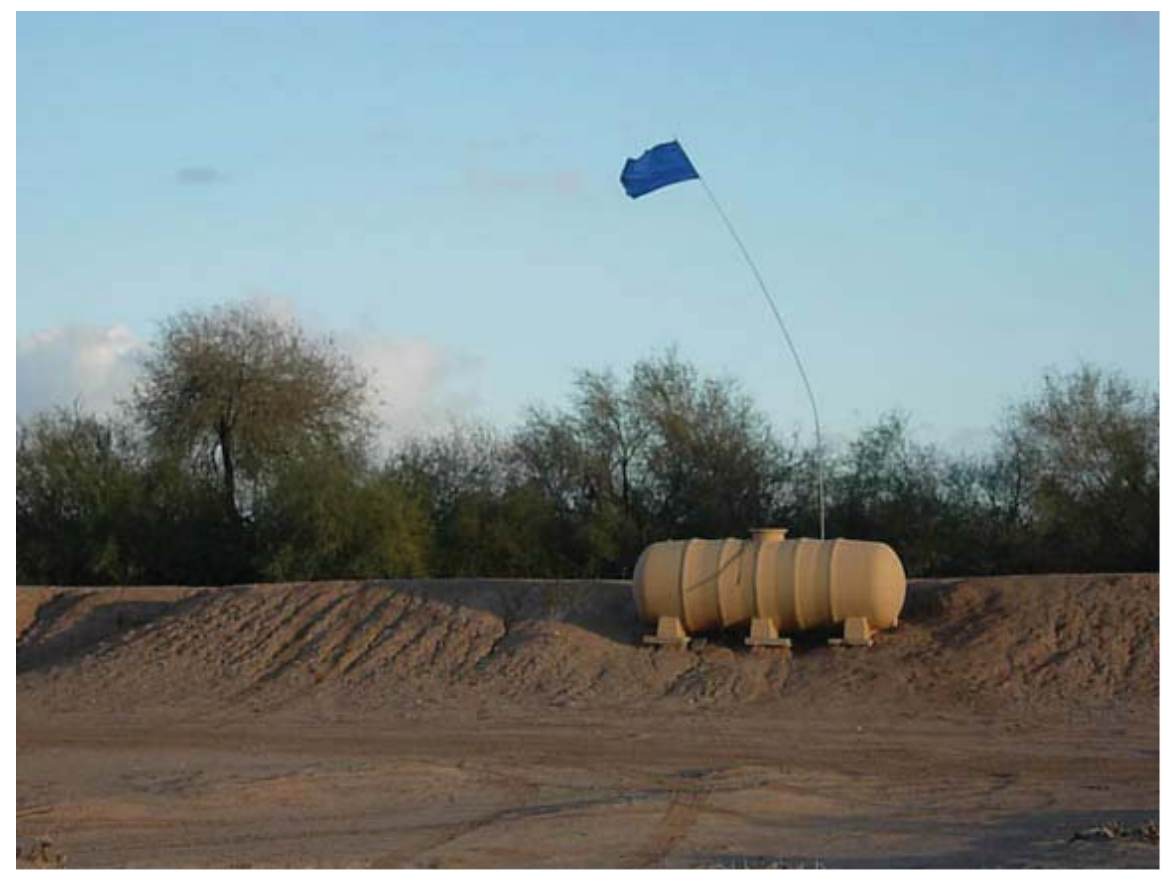

The issue of supplementary water is not easy for individual personnel or at the policy level. A previous refuge staff member described his personal moral dilemma on the issue as following: As a conservation manager, he does not want to implement policies that in any way encourage greater amounts of traffic (with the logic that if you provide water you are aiding in a crime and even potentially encouraging more illegal immigration). However, he was also concerned that allowing human supplementary water might encourage more people to cross through the refuge, and then he would in some sense being responsible for their deaths should they not make it across the desert. The manager argued that the use of rescue beacons offers a more "humane" system of aiding border-crossers. The beacons are scattered throughout the refuge and, should someone run out of water and find themselves in trouble, they simply push the button, and Border Patrol will rescue them (see Figure 4). Or course, this presents its own moral dilemma for the bordercrosser, because if they push that button their journey is over; they will be deported.

\section{Discussion}

Preservation of endangered, threatened, and unique species takes on special significance in the border context. While indeed the "politics of moral relationships matter" in immigration issues (Heyman 1998, 2008), the morality of politics in conservation also matters. To frame this analysis, I draw upon Tania Murray Li's discussion of the decision to "make live" or "let die" (2009). In looking at the plight of dispossessed populations in Asia, Li asks "why governing authorities would elect not to intervene when they could, or select one subset of the population for life enhancement while abandoning another" (2009: 66). In the case of colonial India, Li argues that "letting die was not an oversight. Rather, it was a calculated decision, rationalized in terms of the greater good" (2009: 80). In the 
case discussed in this article, on the US-Mexican border, the population selected for life enhancement happens to be wildlife, while the population left to "let die" are humans (and more specifically Mexicans and Latin Americans suffering their own plight of dispossession).

It is from this angle - a review of current policies of access and denial at Cabeza Prieta — that I examine the issue of water distribution at the refuge. This does not negate the problem of undocumented immigration itself: Of course the process of modern-day border crossing is problematic. Clearly this process represents real danger to health and life as many scholars and human rights advocates have noted (e.g. Annerino 1999; Regan 2010; Urrea 2004). By focusing this article on a seemingly "micro" issue specific to one place and one time along the border, I do not intentionally leave out discussion or critique of the prevention through deterrence immigration policy in place in the United States (Dunn 2009). Instead, I explore a question of moral negotiation: What is the significance of a conservation policy that essentially prioritizes providing water to endangered wildlife rather than supplying water to "in-dangered" people?3 It is in the grey area between these concepts "endangered" and "in-dangered" that moral negotiations are most visible. From this perspective, the policy over supplementary water suggests that immigrant lives are in many ways expendable (Inda 2008).

This framing of the issue leads to an uncomfortable question: Is it possible that the lives of undocumented immigrants are expendable in the name of wilderness regulation? Are issues of race, ethnicity, and nationality an underlying subtext in water policies? Race is a "crucial dimension" of conservation-based dispossession (Li 2009: 76) and racial politics are always present in the policies along the US-Mexico border (Hill 2006; Sundberg and Kaserman 2007; Chavez 2008; St. John 2011; Meierotto 2012). Issues of race, ethnicity, and inequality are also always looming under the surface (if not glaringly on the surface) in the process of nature conservation (Peluso and Watts 2001; Brechin et al. 2003; Kosek 2006; Lowe 2006).

Figure 4. Photo of rescue beacon (taken by author, Lisa Meierotto).

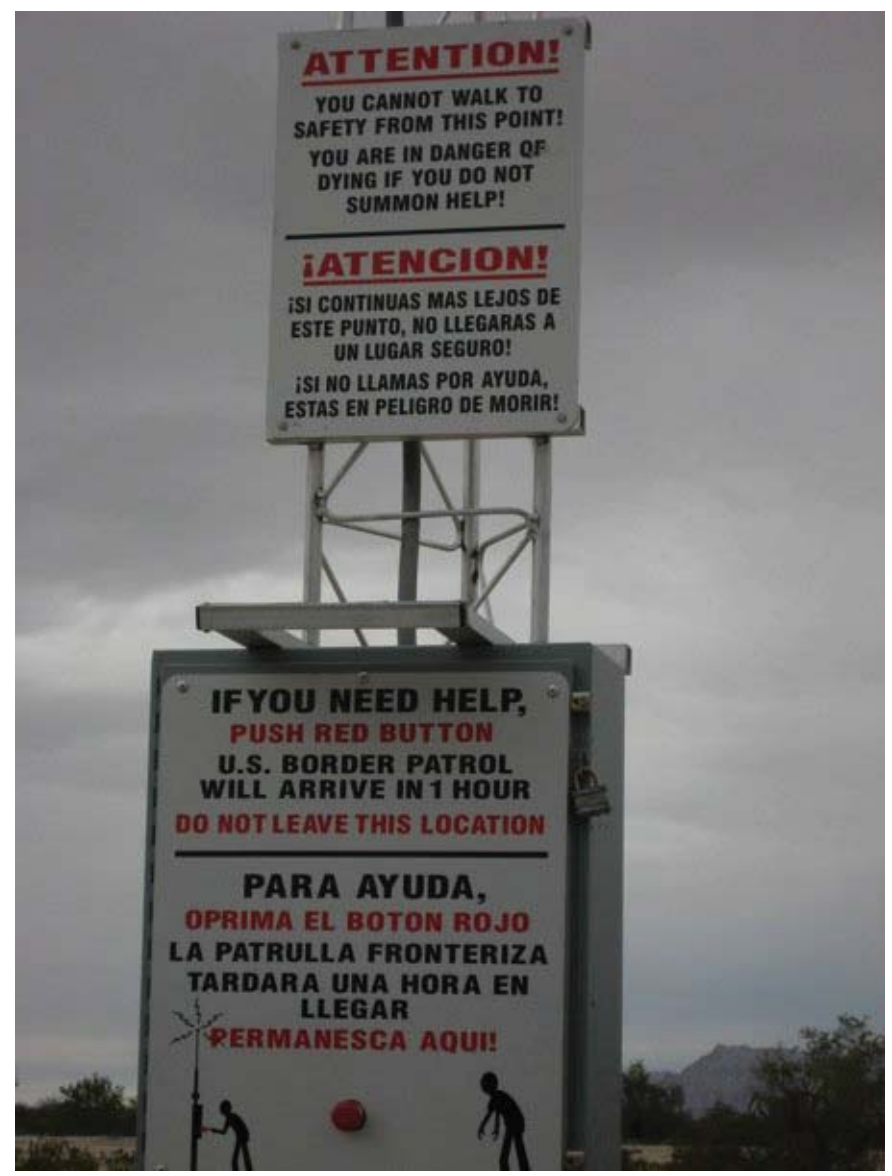


Perhaps the most well-known case of these types of human and environmental tensions is seen in allegations of racism in the advocacy work of the Sierra Club. In the 1990s, the Sierra Club was criticized as being anti-immigrant and racist (Clarke 2001). In recent years, critics acknowledge that the organization appears to have taken a more progressive stance on immigration policy and to have better articulated many human aspects of nature conservation. The Sierra Club now recognizes the human cost of current border and immigration policy in addition to the environmental costs, and supports broad immigration reform (Sierra Club 2001).

\section{Analyzing Priorities—The Dehumanization of Undocumented Immigrants}

The negotiation of conflicting moral narratives over supplementary water at Cabeza Prieta is grounded in ideas about the value of human life. Specifically, recent scholarship on Mexican-origin immigration suggests that immigrants are viewed both as culturally threatening (Chavez 2008; Inda 2008) and environmentally threatening (Hill 2006; Sundberg and Kaserman 2007; Meierotto 2012). In this last section of the article, the discourse of the pursuit of border-crossers is analyzed with the aim of illustrating ways in which language and discourse are integral but often overlooked components of competing moral narratives about supplementary water. Dehumanization of border-crossers is especially noticeable in the pursuit of undocumented migrants by Border Patrol and refuge law enforcement officers. Specific derogatory terms as well as the catch-and-release process utilized by Border Patrol cumulatively serve to dehumanize migrants, and this aids in resolving the moral dilemma of supplementary water. In short, if immigrants and smugglers are alien or less-than-human, the ethical imperative to supply them water diminishes.

In the Brown Tide Rising, Otto Santa Ana (2002) studies discourse of metaphors depicting Latinos. He argues that during immigration reforms of the 1990s, the public image of Latinos transformed. I argue that the combination of conservation and security pressures along the border contributes to the perception of the "dirty Mexican" and helps to perpetuate long-standing and deeply held racialized stereotypes about Mexican immigrants (see also Sundberg and Kaserman 2007). During my fieldwork at the refuge, as well as during observations conducted with border patrol, I encountered many linguistic examples of the dehumanization of Mexicans. Some of the more dramatic examples include the use of terms to describe an undocumented immigrant:

- Body;

- Alien;

- Illegal;

- Migrant;

- UDA (undocumented alien);

- Wetback;

- OTM (other than Mexican).

Each of these terms serves to dehumanize the individual border-crosser. For example, Border Patrol uses the word "body" to describe the presence of an individual crossing through the border. This term is used regardless of whether or not the individual is alive or deceased. For example, you might hear over the radio "we've got a body in the western valley." This does not mean that officers have found a dead body, but rather there is a border-crosser in the valley and the Border Patrol will try to intercept him or her.

The word "alien" of course conjures up an idea of another-world being, someone who is clearly not quite human. Often the expression is shortened from "illegal alien" to just "illegals." For example, an employee, agent, or tourist returning from the refuge might say "I spotted a couple of illegals along Interstate 8 on my way back today."

Perhaps one of the simplest sources of dehumanization of Mexicans is the omission of the word "immigrant" when referring to border-crossers. The word immigrant is a legal term, defined as "a: a person who comes to a country to take up permanent residence b: a plant or animal that becomes established in an area where it was previously unknown" (Merriam Webster Online Dictionary 2009). A migrant is defined as "a: a person who moves regularly in order to find work especially in harvesting crops b: an animal that shifts from one habitat to another" (Merriam Webster Online Dictionary 2009). Mexicans, then, as the identity of the border-crosser, are inherently defined as transitory, shifty, and animalistic. The label "migrant" remains even though many Mexicans today are immigrants 
and not migrants in a temporary sense.4 It is estimated that because crossing the border has become much more difficult since the 1990 immigration policy changes, more Mexicans are choosing to stay in the United States and not return to Mexico on a cyclical basis (Camacho 2006: 836).

It is fascinating to contrast this perception with contemporary and historical references to Mexicans living in the area and passing though the area. For example, when referring to European movement through the region (in contrast to the Native American movement) across Cabeza Prieta, Ahlstrom refers to the Camino as a "travel corridor" (2001: 117). Thus, Europeans travelled through the region, but Mexicans migrated. The perceived migratory nature of Mexican people contributes to the belief that Mexicans are inherently environmental degraders (Meierotto 2012). Biologists assume that "a circumscribed and bounded resource control, not movement [are] essential for maintaining biological diversity and resource abundance" (Lowe 2006: 86). Their presence as an "extraterrestrial other" (Lowe 2006: 81) seems at first to conflict with the perception of Mexicans as closer to nature (Sundberg and Kaserman 2007). But if we think of closeness to nature as "uncivilized" then their presence as a dangerous interloper becomes easier to understand.

There are historical references to migrants in the region as conniving and "shadowy." In this passage, the authors are referring to indigenous people of the region, but the themes of transitory migrants and suspect people echo current stereotypes: [T] he most likely explanation is the existence of a group of desert dwellers contemporaneous with the better known farming cultures. These shadowy people were highly opportunistic, adopting traits from all who surrounded. They also were quite mobile, as suggested by their simple material culture. The vast territory covered by these bands put them in contact with all their neighbors, making them the ideal middlemen to help transport the resources of the desert to their riverine cousins. (Altschul and Rankin 2008: 23, emphasis added) This quote refers to indigenous populations before the border as we know it now even existed. However, there are striking similarities between this passage and current perceptions of border-crossers today. Neither current immigration policy nor popular culture easily or readily distinguishes between Indigenous Mexican people, Mestizo Mexicans, or Spanish/European Mexicans. Instead, they tend to be lumped into the same shifty, mobile, opportunistic people, especially in reference to the "illegals."

The most common term used to describe a border-crosser among conservationists and land-use managers is "UDA," an acronym for "undocumented alien." One local newspaper, the Ajo Copper News, posts articles weekly about the state of affairs of illegal immigration and border enforcement. The following describes a very typical article (there is some version of this article in virtually every installment of Ajo Copper News). For example: "Body of UDA found near Ajo" and an excerpt reads: "US Border Patrol found the body of an illegal immigrant last week near Ajo. Agents said they found foot sign, located the body, and referred the case to the Pima County Sheriff's Department" (Ajo Copper News 2008: 12). The use of the term UDA serves to obscure the fact that a human being has just died, probably a slow and painful death of dehydration while lost in the desert. Popular writer Urrea writes, "Of course, illegals have always been called names other than human—wetback, taco-bender" (2004: 35). Official government names have changed from illegal alien to undocumented worker and more recently undocumented entrant (Urrea 2004).

Migrants are often cast in a negative light and one way this is done is through the use of water metaphors. The use of water metaphors captures the "natural essence" (Hill 2006: 785) of Mexicans. An online blog, "Flooding of the Border with Security Preserves" notes the irony of flood-immigration metaphors and highlights rhetoric typically used to describe the "flows" of people moving around the globe. For example, several idioms are used in the media popular language to discuss migrant movements (Finoki 2008):

- Floods of migrants;

- Deluge of border crossers;

- The waves of refugees.

This type of water imagery is used in a sensationalistic and hyperbolic manner to fortify the perception of the Mexican immigrant as a threat (Hill 2006: 785).

In early 2008, I joined a group of volunteers for a camping trip on the refuge. This trip afforded me an opportunity to see just how deeply embedded the dehumanization of Mexicans is in our everyday language discourse. The campfire discussion that night was fascinating and illuminating. I had the impression of a group of fishermen sitting 
around the camp fire telling stories about fishing and hunting. However, on this occasion, we were sharing stories about UDAs we had encountered while out on the refuge. Three people lamented that while at work in the wilderness, they had yet to see a migrant. But they did see lots of "traces." The campers described this in much the same way that a hunter or wildlife observer would describe finding scat or footprints. The droppings of UDAs include plastic water bottles, tin cans from food, and discarded clothing and backpacks.

Footprints are followed much as one would track an animal (i.e., to determine direction, group size, and proximity of border-crossers). People around the campfire noted both their excitement at seeing a "sign" and how rare it is to see actual people crossing, as this process often takes place in the darkness of night.

Later in the evening, we were talking about one of Cabeza Prieta's endangered species: lesser long-nosed bats. One person brought up that there are stories of UDAs "bedding down" in mine shafts and that this disturbs the endangered bats. It struck me as interesting that he would use the expression "bedding down." In standard, everyday language, we refer to people sleeping or resting or even taking a nap. But migrants apparently "bed down." One of the older men in our group, who has been coming to the refuge for many years, had a wealth of stories about finding different migrants wandering about. He told the story about "the big fish that got away.” This was a story told with great gusto about the time he "found one in a wash" who ran away before he had time to make contact with the individual. He was essentially boasting to the rest of us about how many UDA encounters he had had over the years. But, most interestingly, in the telling of his story he continually used the word UDA in a third person or nonhuman way. For example, instead of saying, "I found a person in a wash," he found "one" in a wash. He also told a story about a volunteer who once picked up a piece of corrugated tin on the ground and was scared half to death when there was a UDA sleeping underneath. Only he did not reference a person sleeping, he instead said there was a "UDA bedding down" under the corrugated tin refuse.

There are many other hunting and fishing metaphors utilized by Border Patrol officers in the pursuit of bordercrossers. The image of a Border Patrol agent holding binoculars, searching for movement on the horizon with his gun in his holster or an automatic weapon hanging on his shoulder, evokes the image of a hunter. The innumerable watch towers along southern Arizona highways are like bird hunting towers, offering a privileged location from which to survey the landscape (see image above). But what struck me the most while doing fieldwork was how this hunting metaphor has spread out to the larger local culture and is no longer exclusively in the domain of law enforcement. One of the most popular activities on the refuge is wildlife observation. Often when I was in town or out on the refuge, it was apparent that watching for Mexicans was an equally compelling and entertaining activity. This armchair "sport" is "a new leisure activity, one that doubles as civic duty" (Juffer 2006: 664). I have to admit, I got caught up in the sport as well, as did the many visitors who accompanied me to Ajo or nearby areas. Our eyes constantly scan the horizon for signs of movement, javelina, mountain lion, or Mexican - they are all equally exciting. Some of my out-of-town guests visiting the region who did not see an "illegal" were "disappointed," and I felt as if I had failed to properly entertain, as if I were a bad hostess. This sense of failure was evident from conversations I had with volunteers, who at times lamented the fact that they have never seen a UDA while on the refuge. It was akin to going fishing or hunting for the day but returning home empty-handed.

\section{Conclusion}

The geopolitical location of Cabeza Prieta on the US-Mexico border inherently draws it into larger immigration issues, and the goal of this article is to situate human rights discourse within conservation discourse. The hesitancy towards humanitarian aid for undocumented border-crossers in wilderness may run deeper than a simple desire to protect the environment from border-traffic. This approach challenges deeply held ideas about who, and what, belongs in wilderness. "Representations and interpretations of threats to nature in border-protected areas repeatedly define that which is threatened as American. Laden with identity attachments, such discourses work to draw boundaries around the nation, thereby narrating inclusion and exclusion” (Sundberg and Kaserman 2007: 4). In the case of Cabeza Prieta, endangered and threatened wildlife belong and are worthy of preservation, but undocumented in-dangered people do not belong and thus their neglect is justifiable. The issue of supplementary water at Cabeza Prieta highlights the complexity of conservation on our nation's southern border and how conflicting values and priorities are negotiated on a daily basis. This controversial topic brings to light multiple moral questions: How do we accomplish wilderness conservation in a militarized and highly politicized context? What is the moral imperative of species conservation in an arid and increasingly hot desert, one that is becoming more hot and arid as a result of global climate change? And finally, what is the value of human life? Does providing supplementary water encourage 
greater border crossing through the desert, or is there a moral imperative to make it available? There are no easy answers, but this is the reality of "doing" conservation on the border. Conservation is a "biopolitics of planetary survival” (Li 2009: 76) and, in this case, juxtaposes issues of ecosystem survival, wildlife preservation, and management, as well as human rights.

Recent changes to US Fish and Wildlife policy may impact the future of water availability for human migrants. In 2010, a compatibility determination was released by the federal government that allows individual groups to request permits for stationary, 55-gallon water drums for migrant water as long as they are located near roads and in already disturbed areas (McCombs 2010). It remains to be seen whether humanitarian groups will petition for the right to place water in Cabeza Prieta, and whether refuge policy will be amended to allow for this.5 There are currently three water tanks in nearby Buenos Aires National Wildlife Refuge, so there is a precedent for potable human water on wildlife refuges.

Conservationists are justifiably concerned that allowing supplementary water for humans might lead to an increase in traffic and litter in environmentally sensitive areas. However, the actual impact of migrant trash is not a pressing environmental concern for the refuge (as compared to other environmental impacts of undocumented immigration and subsequent enforcement activities; see Meierotto 2012). So ultimately, the question of providing water, whether to humans or wildlife becomes a moral and ethical question: To what extent should conservation managers alter wilderness? Is there a moral obligation to supply water to wildlife, especially in the context of human-induced global environmental change? Is there a moral imperative to simultaneously provide water for humans (especially those facing great risk of death) on the refuge? There is a value in seeking to understand overlaps in conservation policy, human rights, and moral dilemmas, and the issue of supplementary water provides an opportunity to explore those overlaps.

\section{Notes}

1. Estimates on the number of deaths of border-crossers varies. McCombs (2010) estimates that there have been over 2,000 border-crosser deaths since 2001.

2. A notable exception is nearby Buenos Aires National Wildlife Refuge, where humanitarian aid groups have negotiated water disbursal sites (McCombs 2010).

3. Thanks to Rebecca Witter for suggesting the term "in-dangered" people.

4. It should also be noted that many in the pro-immigrant/pro-migrant advocacy community, including an anonymous reviewer of this article, have on some occasions for very good reason decided to emphasize the right to temporary transnational movement across the US-Mexico border. This can be indicated by the choice of the word "migrant" rather than "immigrant." This serves to increase the legitimacy of this transnational movement and cyclical migration between Mexico (and elsewhere in Latin America) and the United States.

5. At the time this article went to press in Spring 2015, current refuge policy remains similar to what is described in this article. There are six water sites currently flagged by Humane Borders within the boundaries of the refuge. Discussion and negotiation between refuge staff and humanitarian groups continue.

\section{References}

AHLSTROM, Richard (ed.). (2001) A Cultural Resources Overview and Assessment for the Cabeza Prieta National Wildlife Refuge (Tucson, AZ: SWCA Cultural Resources Report).

AJO COPPER NEWS. (2008) Body of UDA Found Near Ajo. 30 April, p. 12.

ALTSCHUL, Jeffrey H., and RANKIN, Adrianne G. (eds.). (2008) Fragile Patterns: The Archaeology of the Western Papagueria (Tucson, AZ: SRI Press).

AMBROS-MARCIAL ET AL. V. UNITED STATES. (2005) 377 F. Supp. 2d 767 (D. Arizona). [Online]. Available: https://www.animallaw.info/case/ambros-marcial-v-us [5 February 2015].

ANDREAS, Peter. (2009) Border Games: Policing the United States-Mexico Divide, 2nd ed. (Ithaca, NY: Cornell University Press).

ANNERINO, John. (1999) Dead in their Tracks: Crossing America’s Borderlands (New York: Four Walls Eight Windows).

BEAIL-FARKAS, L. (2013) The human right to water and sanitation: Context, contours, and enforcement prospects. Wisconsin International Law Journal, 30(4), 761-801. 
BRECHIN, Steven, WILSHUSEN, Peter, FORTWANGLER, Crystal, and WEST, Patrick. (2003) Contested Nature: Promoting International Biodiversity and Social Justice in the Twenty-First Century (New York: State University of New York Press Albany).

BROYLES, B. (1995) Desert wildlife water developments: Questioning use in the Southwest. Wildlife Society Bulletin, 23(4), 663-675.

BROYLES, B., and CUTLER, T. L. (1999) Effect of surface water on desert bighorn sheep in the Cabeza Prieta National Wildlife Refuge, Arizona. Wildlife Society Bulletin, 27(4), 1082-1088.

CAMACHO, Alicia Schmidt. (2006) Migrant melancholia: Emergent discourses of Mexican migrant traffic in transnational space. South Atlantic Quarterly, 105(4), 831-861.

CHAVEZ, Leo. (2008) The Latino Threat: Constructing Immigrants, Citizens, and the Nation (Stanford, CA: Stanford University Press).

CLARKE, A. (2001) The Sierra Club and immigration policy: A critique. Politics and the Life Sciences, 20(1), 1928.

CORNELIUS, Wayne. (2001) Death at the border: Efficacy and unintended consequences of US Immigration control policy. Population and Development Review, 27(4), 661-685.

CRONON, William. (1996) Uncommon Ground: Rethinking the Human Place in Nature (New York: W.W. Norton and Company).

DOLAN, Brian. (2006) Water developments and desert bighorn sheep: Implications for conservation. Wildlife Society Bulletin, 34(3), 642-646.

DUNN, Timothy J. (2009) Blockading the Border and Human Rights: The El Paso Operation that Remade Immigration Enforcement (Austin: University of Texas Press).

Environmental Protection Agency. (2013) Climate Impacts in the Southwest. [Online]. Available: http://www.epa.gov/climatechange/impacts-adaptation/southwest.html [26 January 2015].

HEYMAN, Josiah. (1998) Finding a Moral Heart for U.S. Immigration Policy: An Anthropological Perspective (Arlington, VA: American Anthropological Association).

HEYMAN, Josiah. (2008) Tough questions in the US immigration debate: Finding a moral heart for US immigration policy revisited. Anthropology News, 49(5), 10-11.

HILL, Sarah. (2006) Purity and danger on the U.S.-Mexico border 1991-1994. South Atlantic Quarterly, 105(4), 777-800.

HUMANE BORDERS. (2015) [Online]. Available: http://www.humaneborders.org [26 January 2015].

INDA, Jonathan. (2008) The value of immigrant life. In Women and Migration in the US-Mexico Borderlands: A Reader, Denise A. Segura and Patricia Zavella (eds.) (Durham, NC: Duke University Press). Human Rights on the US-Mexico Border 17 Downloaded by [75.167.191.133] at 10:09 23 March 2015

JUFFER, Jane. (2006) The last frontier: The contemporary configuration of the U.S.-Mexico border - Introduction. South Atlantic Quarterly, 105(4), 663-680.

KOSEK, Jake. (2006) Understories: The Political Life of Forests in Northern New Mexico (Durham: Duke University Press).

LACEY, Marc. (2010, September 28) Water drops for migrants: Kindness, or offense? New York Times, U.S. Section. [Online]. Available: http://www.nytimes.com/2010/09/27/us/27water.html?çrD3\&refDglobalhome [26 January 2015].

LI, Tania. (2009) To make live or let die? Rural dispossession and the protection of surplus populations. Antipode, 14(6), 1208-1235.

LOWE, Celia. (2006) Wild Profusion: Biodiversity Conservation in an Indonesian Archipelago (Princeton: Princeton University Press).

MARIL, Robert L. (2011) The Fence: National Security, Public Safety, and Illegal Immigration Along the U.S.Mexico Border (Lubbock, TX: Texas Tech University Press).

MARTINEZ, Oscar J. (2006) Troublesome Border (Tucson: University of Arizona Press).

MATTSON, David J., and CHAMBERS, Nina. (2009) Human-provided waters for desert wildlife: What is the problem? Policy Sciences, 42(2), 113-135.

MCCOMBS, Brady. (2010, September 4) 55-gallon drums for migrants are OK'd, but rules will be strict US allows new water stations by border. Arizona Daily Star. [Online]. http://tucson.com/news/local/border/us-allowsnew-water-stations-by-border/article_a8dc1191-74fc-5a8a-9ad0-409b7a1e8b65.html [26 January 2015].

MEIEROTTO, Lisa. (2012) The blame game on the border: Perceptions of environmental degradation on the U.S.Mexico Border. Human Organization, 71(1), 11-21.

MERRIAM WEBSTER ONLINE DICTIONARY. (2009) [Online]. Available: http://www.merriam-webster.com [26 January 2015]. 
NEVINS, Joseph. (2002) Operation Gatekeeper: The Rise of the "Illegal Alien" and the Making of the U.S.-Mexico Boundary (New York: Routledge).

PELUSO, Nancy, and WATTS, Michael. (2001) Violent Environments (Ithaca: Cornell University Press).

PIVETTI, Monica. (2005). Animal rights activists' representations of animals and animal rights: An exploratory study. Anthrozoos, 18(2), 140-159.

REGAN, Margaret. (2010) The Death of Josseline (Boston: Beacon Press).

SANTA ANA, Otto. (2002) Brown Tide Rising: Metaphors of Latinos in Contemporary American Public Discourse (Austin: University of Texas Press).

SIERRA CLUB. (2001) Sierra Club Borderlands. [Online]. Available: http://www.sierraclub.org/borderlands/overview.aspx [28 February 2014].

ST. JOHN, Rachel. (2011) Line in the Sand: A History of the Western U.S.-Mexico Border (Princeton: Princeton University Press).

SUNDBERG, Juanita, and KASERMAN, Bonnie. (2007) Cactus carvings and desert defecations: Embodying representations of border crossings in protected areas on the Mexico-US Border. Environment and Planning D: Society and Space, 25(4), 727-744.

UNITED NATIONS. (2010) United Nations General Assembly: Resolution adopted by the General Assembly on 28 July 2010. [Online]. Available: http://www.un.org/es/comun/docs/?symbolDA/RES/64/292\&langDE [28 February 2014].

UNITED STATES FISH AND WILDLIFE SERVICES, DEPARTMENT OF THE INTERIOR. (2007) Cabeza Prieta National Wildlife Refuge Comprehensive Conservation Plan, Wilderness Stewardship Plan and Environmental Impact Statement (Albuquerque: Division of Planning, National Wildlife Refuge System, Southwest Region).

UNITED STATES GOVERNMENT ACCOUNTABILITY OFFICE (USGOA). (2006) Illegal immigration BorderCrossing Deaths Have Doubled Since 1995; Border Patrol's Efforts to Prevent Deaths Have Not Been Fully Evaluated. [Online]. http://www.gao.gov/products/GAO-06-770 [26 January 2015].

URREA, Louis Alberto. (2004) The Devil’s Highway: A True Story (New York: Little Brown and Company). 